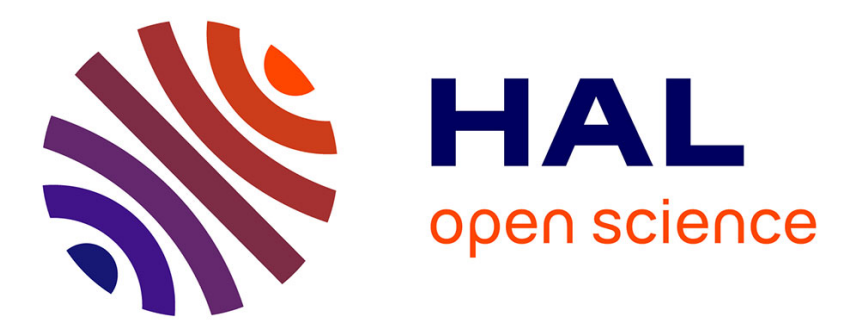

\title{
Proposal for a smart pressurised ring test to study thick composite produced by filament winding
}

Christophe Bois, Aurélie Pilato, Jean-Christophe Wahl, Nicolas Perry

\section{To cite this version:}

Christophe Bois, Aurélie Pilato, Jean-Christophe Wahl, Nicolas Perry. Proposal for a smart pressurised ring test to study thick composite produced by filament winding. Composites Part B: Engineering, 2013, 53, pp.382-390. 10.1016/j.compositesb.2013.06.001 . hal-00941424

\section{HAL Id: hal-00941424 \\ https://hal.science/hal-00941424}

Submitted on 3 Feb 2014

HAL is a multi-disciplinary open access archive for the deposit and dissemination of scientific research documents, whether they are published or not. The documents may come from teaching and research institutions in France or abroad, or from public or private research centers.
L'archive ouverte pluridisciplinaire HAL, est destinée au dépôt et à la diffusion de documents scientifiques de niveau recherche, publiés ou non, émanant des établissements d'enseignement et de recherche français ou étrangers, des laboratoires publics ou privés. 


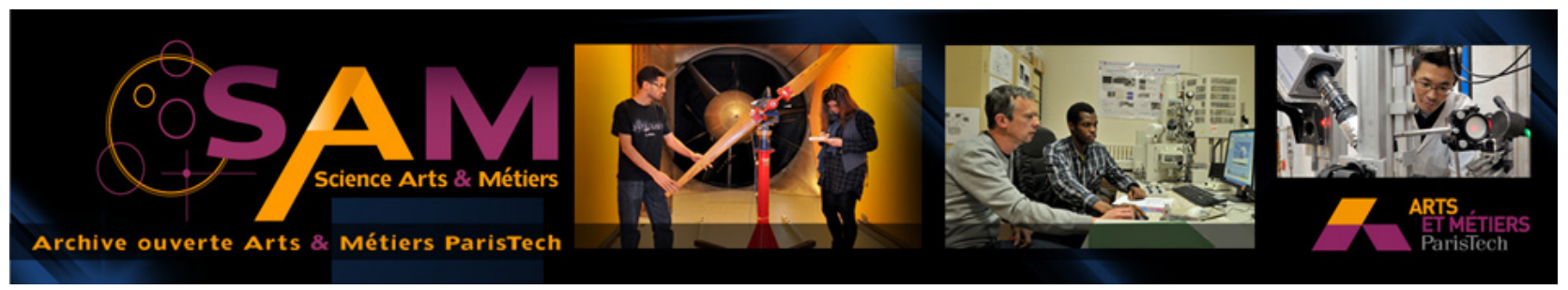

Science Arts \& Métiers (SAM)

is an open access repository that collects the work of Arts et Métiers ParisTech researchers and makes it freely available over the web where possible.

This is an author-deposited version published in: http://sam.ensam.eu

Handle ID: .http://hdl.handle.net/10985/7742

\section{To cite this version :}

Christophe BOIS, Aurélie PILATO, Jean-Christophe WAHL, Nicolas PERRY - Proposal for a smart pressurised ring test to study thick composite produced by lament winding - Composites: Part B - Vol. 53, p.382-390 - 2013 


\title{
Proposal for a smart pressurised ring test to study thick composite produced by filament winding
}

\author{
Christophe Bois ${ }^{\mathrm{a}, *}$, Aurélie Pilato ${ }^{\mathrm{a}}$, Jean-Christophe Wahl ${ }^{\mathrm{a}}$, Nicolas Perry ${ }^{\mathrm{b}}$ \\ ${ }^{a}$ Univ. Bordeaux, I2M, UMR 5295, 15 rue Naudet, CS 10207, 33175 Gradignan Cedex, France \\ ${ }^{\mathrm{b}}$ Arts et Métiers ParisTech, I2M, UMR 5295, Esplanade des Arts et Métiers, 33405 Talence Cedex, France
}

Keywords:

A. Carbon fibre

D. Mechanical testing

E. Filament winding

Pressure vessel

\begin{abstract}
A B S T R A C T
Improvements in the characterisation of materials used in pipes, tubes or vessels rely on the development of tests on cylindrical samples in order to be consistent with the real manufacturing process. Existing devices are unable to reach the pressure limits required to test high pressure hydrogen storage tanks. We therefore propose an original test device based on a conical fitting system. First, the operational principle and the pressure measurement technique are presented. Next, the choice of apparatus design parameters according to test requirements is discussed. In addition, the device's capabilities are illustrated on a $39 \mathrm{~mm}$ thick CFRP ring test including Digital Image Correlation measurements.
\end{abstract}

\section{Introduction}

Most improvements in terms of materials characterisation focus on respecting the real manufacturing process. This is why the characterisation of materials used in pipes, tubes or vessels uses cylindrical samples made with the actual process. This is particularly the case for plastic pipes in which polymer extrusion aligns molecules parallel to the extrusion direction or filament-wound composite pipes where the process is not reproducible on a noncylindrical part. Indeed, mechanical properties obtained with a plane sample are not satisfactory. Even if samples are cut from a plate formed on a rectangular mandrel, the material compaction and consequent porosity and fibre fraction will be different [1].

After the design and manufacturing processes, vessel strength can be evaluated by a hydro-burst test, as specified in $[2,3]$. However, this test is quite expensive to implement (pressurising pumps, protection installation, test specimens especially for expensive material, etc.) and slows down the iterative design loop. Moreover, material properties cannot be directly estimated with this type of test, which is a huge drawback for design improvement.

Consequently, several devices were proposed in order to test ring specimens since rings constitute the most suitable intermediate structure. The split disc method [4,5] applied to plastic or composite rings is the one that is most used. In this test, thin rings

\footnotetext{
* Corresponding author. Tel.: +33 5568479 78; fax: +33 556845843 .

E-mail addresses: christophe.bois@u-bordeaux1.fr (C. Bois), aurelie.pilato@ mines-albi.fr (A. Pilato), jean-christophe.wahl@u-bordeaux1.fr (J.-C. Wahl), nicolas.perry@ensam.eu (N. Perry).
}

are loaded up to failure in tension by split discs. The failure is forced to be located at a reduced ring section. Nevertheless, Laiarinandrasana et al. [6] showed that in this test, the hoop stress in the ring is inhomogeneous because of a bending effect and a non-uniaxial loading (generation of radial and longitudinal stresses).

Relatively similar tests are performed on plastic ring specimens for slow cracking detection $[7,8]$. Although these rings are taken from pipes, they are not tested under internal pressure but by bending, which is not representative of the real load.

Thus, several devices [9,10] providing internal pressure on a ring specimen have been developed. They consist of a base plate and a cover plate, and they are designed to load the ring by internal pressure using pressurising fluid. The major difference is that the load is transferred using a rubber bladder containing the fluid $[3,10]$ or an intermediate PTFE ring [9]. This type of fixture provides uniform pressure over the circumference of the ring but needs a good sealing system and high performance hydraulic pumps. These fixtures represent a significant improvement compared to the split disc method. Nevertheless, in practice, the maximal pressure applied is close to 300 bar and limited by the sealing system.

This pressure limit does not fit with the characterisation of composite materials used in high pressure tanks for hydrogen storage. For a storage pressure of 700 bar, safety standards require to design and test the structure with a maximal pressure equal to 2100 bar (safety margin factor equal to 3 ). Consequently, the thickness of the vessel is greater than $30 \mathrm{~mm}$ for a diameter close to 
Table 1

Functional requirements of the test device.

\begin{tabular}{|c|c|c|c|}
\hline \multicolumn{2}{|c|}{ Functional requirements } & \multirow{3}{*}{$\begin{array}{l}\text { Criteria } \\
\text { Maximal internal } \\
\text { pressure } p_{0}^{\max } \\
\text { Maximal internal } \\
\text { radial displacement } \\
u_{0}^{\max }\end{array}$} & \multirow{2}{*}{$\begin{array}{l}\text { Level } \\
700 \text { bar }\end{array}$} \\
\hline $\mathrm{F} 1$ & $\begin{array}{l}\text { Load the tested ring with } \\
\text { uniform pressure }\end{array}$ & & \\
\hline & & & $0.75 \mathrm{~mm}$ \\
\hline & & $\begin{array}{l}\text { Standard deviation on } \\
\text { internal pressure } \sigma_{p}\end{array}$ & $5 \%$ \\
\hline \multirow[t]{2}{*}{ F2 } & $\begin{array}{l}\text { Measure the applied pressure } \\
\text { and internal radial displacement }\end{array}$ & $\begin{array}{l}\text { Pressure measurement } \\
\text { accuracy } \delta p_{0} / p_{0}\end{array}$ & $15 \%$ \\
\hline & & $\begin{array}{l}\text { Displacement } \\
\text { measurement accuracy } \\
\delta u_{0} / u_{0}\end{array}$ & $1 \%$ \\
\hline FC1 & $\begin{array}{l}\text { Able to adapt to a tension/ } \\
\text { compression testing machine }\end{array}$ & $\begin{array}{l}\text { Maximal force } F_{\max } \\
\text { Maximal stroke } d_{\max }\end{array}$ & $\begin{array}{l}100 \mathrm{kN} \\
500 \mathrm{~mm}\end{array}$ \\
\hline $\mathrm{FC} 2$ & Fit the dimensions of tested ring & $\begin{array}{l}\text { Internal radius } r_{0} \\
\text { Height } h\end{array}$ & $\begin{array}{l}155 \mathrm{~mm} \\
15 \mathrm{~mm}\end{array}$ \\
\hline $\mathrm{FC} 3$ & Able to be handled and carried & $\begin{array}{l}\text { Maximal mass of each } \\
\text { part }\end{array}$ & $25 \mathrm{~kg}$ \\
\hline
\end{tabular}

$300 \mathrm{~mm}$. These thick composite structures are generally produced using the filament-wound process at low temperature, without external pressure (autoclave process) and vacuum bag. Thus, this process generates physical material property variations such as void fraction, fibre fraction or matrix modulus through the thickness [1,11-17] that can generate variations in mechanical properties $[14,18-20]$. For design and process improvement purposes, engineers need characterisation at the material scale but also tests at the structure scale in order to evaluate the effects of property variations.

The objective of this study was thus to develop a new device to test thick rings under internal pressure up to in-service load. With the device proposed here it is also possible to observe the lateral faces of the ring in order to quantify the influence of material property variations through the thickness with the help of strain field measurements. The main purpose of this paper is to present and develop the physical elements that drive the design of the test apparatus. First of all, the functional requirements of the test and its operational principles are presented. An original method is proposed to estimate the internal pressure applied to the tested ring. The choice of design parameters is then discussed according to the uniformity and measurement precision of the pressure that constitute the two main test requirements. In addition, to demonstrate the ability of the device to generate high pressure load, an experimental protocol and results on a composite ring extracted from a $39 \mathrm{~mm}$ thick full-scale pressure vessel are presented.

\section{Design of the new and smart pressurised ring test}

\subsection{Functional requirements}

Functional requirements and associated criteria are listed in Table 1. The main function F1 consists in loading the tested ring with a uniform pressure, and the main function F2 consists in measuring the applied pressure and internal radial displacement in order to determine the pressure versus displacement behaviour of the ring to be characterised.

The device is designed to be actuated with a tension/compression testing machine (Functional constraint FC1). This is a way to reduce the cost of the device and increase its versatility. The device is designed to fit the dimensions of the tested ring since its main objective is to perform a test representative of the manufacturing process (Functional constraint FC2).

Values in Table 1 refer to a composite ring $39 \mathrm{~mm}$ thick made of circumferential and various winding angles of carbon fibres and epoxy resin. The maximal pressure and internal displacement were estimated from properties found in documentation from the material supplier. Pressure uniformity and measurement precisions were deduced from usual test standards for polymer matrix composite [21]. Of course, these values should be adapted according to test objectives.

\subsection{Operational principle}

Basically, the device principle consists in transforming the vertical cross head displacement of the testing machine into a radial displacement transmitted to the tested ring. The device proposed is described in the physical view in Fig. 1 and in a functional and design view in Fig. 2. A male cone deforms a female cone by entering into it, which generates a radial displacement on the tested ring. The female cone is put on a rigid support which avoids the vertical displacement of the female cone and the tested ring. With a small cone angle, the load supplied by the standard testing machine can be amplified in order to apply high pressure. Fig. 2 sums up the different loading transmission blocks, functional requirements and design parameters of the device system.

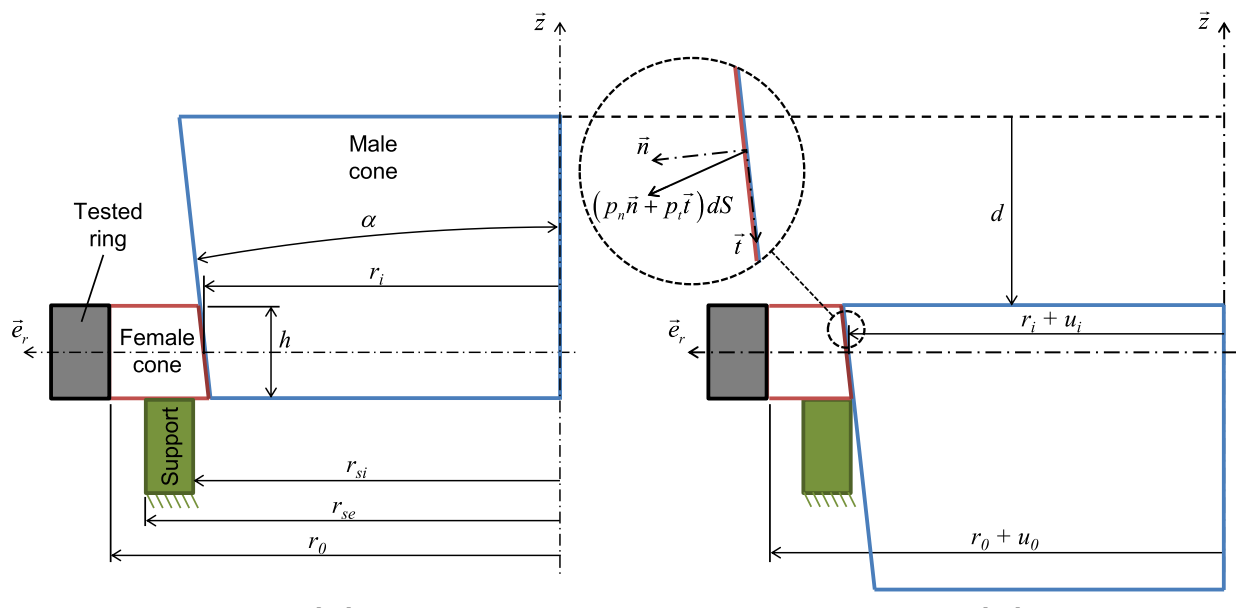

(a)

(b)

Fig. 1. Description of the test device: (a) at the beginning of the test; and (b) at the end of the test 


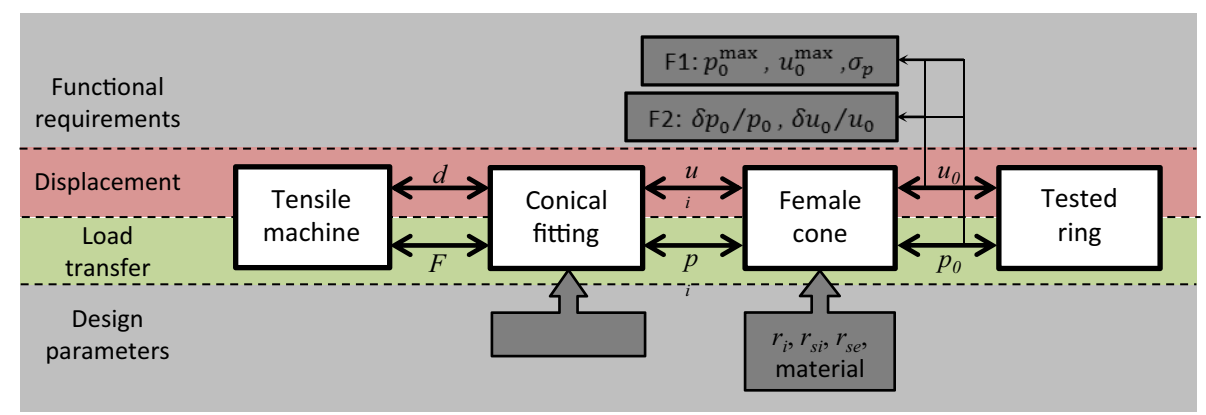

Fig. 2. Displacement and load transfer in the test device and interaction with design parameters and functional requirements.

\subsection{Pressure measurement}

While the external displacement applied to the tested ring can be easily obtained from LVDT sensors for thin rings or optical measurement (Digital Image Correlation) for thick rings, the pressure applied needs an indirect solution. Two ways were investigated: the first consists in using the testing machine load cell and the second in using the female cone as a load sensor by measuring its internal and external radial displacements.

A typical machine load versus time curve is plotted in Fig. 3. Even with a highly efficient lubrication between the two cones, a stick slip phenomenon occurs during the test. As shown in Fig. 3, lower, upper and mean wrap curves can be extracted from the untreated measurement in order to estimate the pressure applied to the ring. However, determining the pressure depends on knowing the sliding coefficient between male and female cones, which is highly dependent on lubrication conditions, contact pressure and sliding velocity. It therefore becomes difficult to propose a model which could be used to extract the pressure applied to the ring. It is even more disturbed because the friction load represents a large proportion of the total load. This first way was thus excluded.

The second way to evaluate the pressure applied to the ring, which we investigate and develop in this paper, consists in using the female cone as a load sensor. This method is based on an analytical model of the female cone deformation in which elastic properties are assumed to be known. By measuring both internal displacement (deduced from crosshead machine and cone angle) and external displacement of the female cone obtained with Digital Image Correlation, the pressure applied by the tested ring is

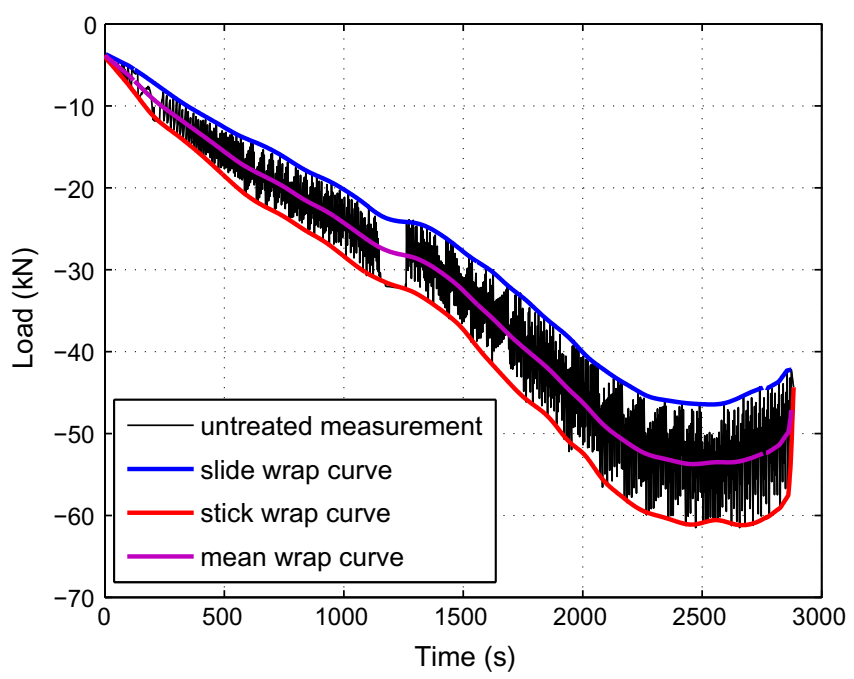

Fig. 3. Typical load versus time curve during the ring test. indirectly measured The analytical equations used and the uncertainty study are detailed below, with the discussion on the choice of design parameters.

\subsection{Dimensioning methodology}

The operational principle of the ring test is quite simple, but the performance of the device depends on a judicious choice of design parameter values as listed below:

- Conical fitting:

- Cone angle: $\alpha$

- Female cone:

- Material: modulus $E$, Poisson coefficient $v$, yield stress $\sigma_{e}$

- Mean internal radius: $r_{i}$

- Support of the female cone

- Internal radius: $r_{s i}$

- External radius: $r_{s e}$

These design parameters need to satisfy functional requirements (Table 1). As described in Fig. 2, the relation between design parameters and functional requirements depends on displacement and load transfer through each part of the test device. In order to obtain these relations, we used two models. The first is a 1-D analytic model which gives the relation between:

- The tensile machine displacement $d$ and internal radial displacement of the female cone $u_{i}$,

- The testing machine force $F$ and internal pressure of the female cone $p_{i}$,

- The internal and external pressure and displacement applied to the female cone $p_{i}, p_{0}, u_{i}$ and $u_{0}$.

In this model, all the pressure and displacement are assumed uniform in the height $h$ of the tested ring.

The second model is a 2-D axisymmetric Finite Element Model (FEM). It is used to quantify the non-uniform field of pressure and displacement applied to the internal surface of the tested ring. It is also used to validate the analytic model and identify the more loaded areas in the female cone and then verify if the material yield stress is exceeded.

\section{Description of models}

\subsection{Analytical model}

The contrast between the male cone and the female cone suggests that the vertical displacement $d$ of the testing machine is directly imposed on the female cone. The internal displacement $u_{i}$ can be calculated as follows:

$u_{i}=d \tan (\alpha)$ 
In addition, as shown in Fig. 1, the contact force pressure $\overrightarrow{d F}$ between the male and the female cones can be defined as the sum of a normal pressure $p_{n}$ and a tangential pressure $p_{t}$ :

$$
\overrightarrow{d F}=p_{n} \vec{n}+p_{t} \vec{t}
$$

If $f$ is the sliding coefficient between the two cones, the tangential pressure can be expressed from the normal pressure as follows:

$p_{t}=f p_{n}$

The machine load can then be calculated:

$$
\begin{aligned}
F & =\left[\iint_{S c} \overrightarrow{d F d S}\right] \cdot \vec{z}=\left[\iint_{S c} p_{n} \vec{n}+p_{t} \vec{t} d S\right] \cdot \vec{z} \\
& =p_{n}(\sin \alpha+f \cos \alpha) S_{c}
\end{aligned}
$$

where $S_{c}$ is the contact surface between the male and the female cones.

Considering that the cone angle is low, the female cone is modelled as a thick ring. By assuming a linear elastic behaviour for the material of the female cone, the internal displacement $u_{i}$ and the external displacement $u_{0}$ can be calculated from the internal pressure $p_{i}$ and the external pressure $p_{0}$ applied to the female cone by the tested ring:

$u_{i}=s_{i i} p_{i}+s_{i 0} p_{0}$

$u_{0}=s_{0 i} p_{i}+s_{00} p_{0}$

Constants $s_{i i}, s_{i 0}, s_{0 i}$ and $s_{00}$ depend on the internal radius $r_{i}$, the external radius $r_{0}$, the Young modulus $E$ and the Poisson coefficient $v$ of the material:

$s_{i i}=\frac{r_{i}}{E}\left(\frac{r_{i}^{2}+r_{0}^{2}}{r_{0}^{2}-r_{i}^{2}}+v\right)$

$s_{i 0}=\frac{-2}{E} \frac{r_{i} r_{0}^{2}}{r_{0}^{2}-r_{i}^{2}}$

$s_{0 i}=\frac{2}{E} \frac{r_{0} r_{i}^{2}}{r_{0}^{2}-r_{i}^{2}}$

$s_{00}=\frac{r_{0}}{E}\left(v-\frac{r_{i}^{2}+r_{0}^{2}}{r_{0}^{2}-r_{i}^{2}}\right)$

The internal pressure $p_{i}$ can be linked to the normal pressure $p_{n}$ as follows:

$p_{i}=\left(p_{n} \vec{n}+p_{t} \vec{t}\right) \cdot \overrightarrow{e_{r}}=p_{n}(\cos \alpha-f \sin \alpha)$

By transferring Eq. (11) in Eq. (4), we obtain:

$F=p_{i} \frac{\sin \alpha+f \cos \alpha}{\cos \alpha-f \sin \alpha} S_{c}$

Eqs. (1) and (12) describe the behaviour of the conical amplification system (conical fitting), while Eqs. (5) and (6) describe the behaviour of the female cone. These equations are combined further to optimise the choice of cone angle and calculate the pressure applied to the tested ring.

\subsection{Finite Element Model (FEM)}

The model is described in Fig. 4. As for the analytical model, the test device is assumed axisymmetric and the male cone and the support are modelled as rigid bodies. A hard contact with a Coulomb friction law was used to model the interactions between the male and female cones, between the female cone and the support and between the female cone and the tested ring. Linear and non-linear behaviour can be easily implemented for the female cone and the tested ring. FEM results demonstrate that the analytical model is able to predict the pressure applied to the tested ring and the load supplied by the testing machine with an error less than $2 \%$. Results show especially that the displacement imposed by the male cone to the female cone is not altered when the friction coefficient between the female cone and the support changes from 0 to 0.1 . Consequently, the pressure distribution is also not altered. Moreover, the machine load increases less than $1 \%$ when this friction coefficient changes from 0 to 0.1 . That explains why the frictional force between the female cone and the support can be neglected in the analytical model. The FEM was also used next to study the influence of design parameters on fields of pressure and displacement applied to the internal surface of the tested ring.

\section{Test device dimensioning}

\subsection{Choice of female cone material}

At the interface between the female cone and the ring, the radial displacement in the material of the female cone is equal to that in the material of the ring. The hoop strains are therefore also identical in the two materials. Thus, the yield strain of the female cone must be greater than the maximal strain of the tested ring that we want achieve. For example, the strain at failure of carbon fibre composite material is around $1.5 \%$. So, as shown in Table 2 , polymer materials seem to be good candidates to characterise composite rings.

Moreover, with a soft material for the female cone, the proportion of the force supplied by the machine that is used to load the ring is greater. Even if the yield stress of polymer materials appears quite low compared to the pressure required, the stress state in the female cone enables a high proportion of hydrostatic pressure which significantly increases the actual Von Mises yield stress of the polymer material.

\subsection{Choice of cone angle}

From Eq. (12) we can define an non-dimensional amplification factor:

$a_{c}=\frac{p_{i} S_{c}}{F}=\frac{\cos \alpha-f \sin \alpha}{\sin \alpha+f \cos \alpha}$

$a_{c}$ expresses the ability of the conical system to amplify the force supplied by the testing machine. Fig. 5 illustrates the influence of the cone angle on the amplification factor for different friction coefficients. The amplification factor cannot exceed $1 / f$ even if the cone angle is close to 0 . A compromise has to be found

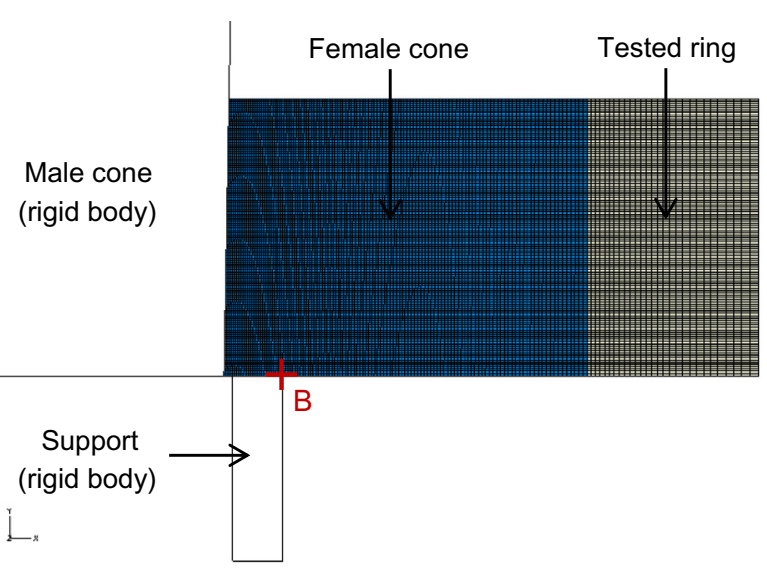

Fig. 4. Description of the axisymmetric finite element model. 
Table 2

Mechanical properties of different materials considered for the female cone.

\begin{tabular}{|c|c|c|c|}
\hline Material & $\begin{array}{l}\text { Young } \\
\text { modulus } \\
(\mathrm{GPa})\end{array}$ & $\begin{array}{l}\text { Yield stress in } \\
\text { tensile test (MPa) }\end{array}$ & $\begin{array}{l}\text { Yield strain in } \\
\text { tensile test (\%) }\end{array}$ \\
\hline $\begin{array}{l}\text { Steel alloy } 36 \mathrm{Ni} \\
\text { Cr Mo } 16\end{array}$ & 210 & 1275 & 0.6 \\
\hline $\begin{array}{l}\text { Aluminium } \\
\text { alloy } 7049\end{array}$ & 70 & 560 & 0.8 \\
\hline Titanium TA6V & 110 & 900 & 0.82 \\
\hline $\begin{array}{l}\text { Polyamide } \\
\text { imide }\end{array}$ & 5 & 60 & 1.2 \\
\hline Polyamide & 3.1 & 70 & 2.3 \\
\hline
\end{tabular}

to ensure an amplification factor close to its maximum $1 / f$ with a small $\alpha$ but with a reasonable height of the male cone in order to limit the size, weight and cost of the male cone and the support. A cone angle of $1^{\circ}$ was selected for the test device.

From Eqs. (6) and (12) we can calculate the maximal load $F_{\max }$ supplied by the tensile machine for a given tested ring (knowing $p_{0}^{\max }$ and $u_{0}^{\max }$ ). Fig. 6 illustrates the influence of the female cone thickness $\left(r_{0}-r_{i}\right)$ on maximal machine load for different friction coefficients and $\alpha=1^{\circ}$. The values used for $p_{0}^{\max }$ and $u_{0}^{\max }$ are given in Table 1 (composite ring $39 \mathrm{~mm}$ thick), and the material of the female cone is a polyamide 6 (PA6). The influence of the female cone thickness on maximal machine load is very limited due to the high contrast of modulus between tested material and female cone material. The curve obtained for $f=0$ confirms that a great proportion of load is dissipated by friction in the conical fitting. As the actual friction coefficient varies between 0.06 and 0.08 , the load capacity of the tensile machine used $\left(F_{\max }=100 \mathrm{kN}\right)$ is enough to reach $p_{0}^{\max }=700$ bar.

\subsection{Choice of internal and external support radius}

The influences of the internal and external support radius on the uniformity of the pressure and displacement applied to the tested ring were studied using the FEM. Several simulations were performed by varying these two parameters from a base configuration where $\alpha=1^{\circ}, h=15 \mathrm{~mm}, r_{i}=61.65 \mathrm{~mm}, r_{0}=81.25 \mathrm{~mm}$, $r_{s i}=62.1 \mathrm{~mm}, \quad r_{s e}=64.8 \mathrm{~mm}, E=3.1 \mathrm{MPa}$ (material PA6) and $v=0.35$ (material PA6). Note that $r_{s i}$ should be greater than $r_{i}$ in order to take into account the higher male cone radius at its maximum vertical displacement. The tested ring consists of a $9.35 \mathrm{~mm}$ thick steel ring.

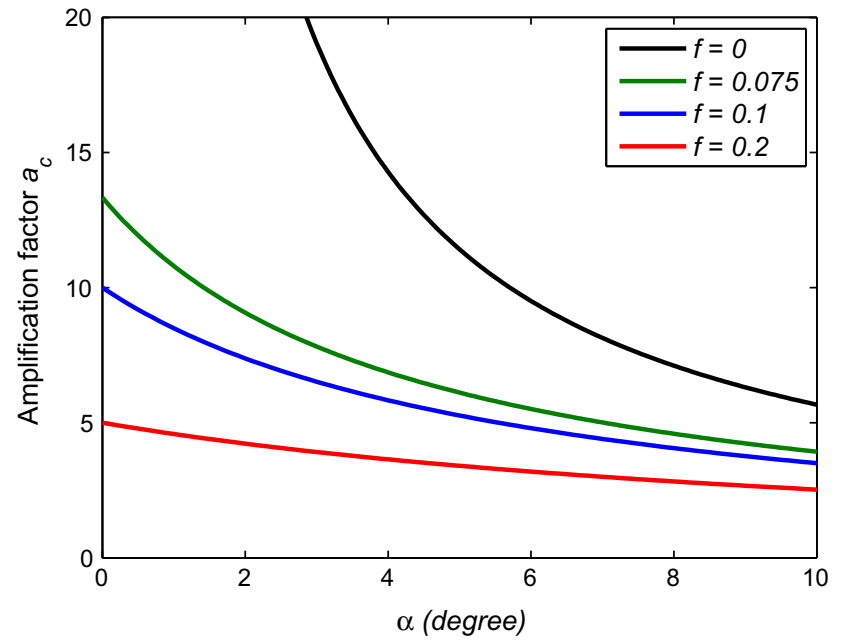

Fig. 5. Influence of the cone angle on the amplification factor for different friction coefficients.

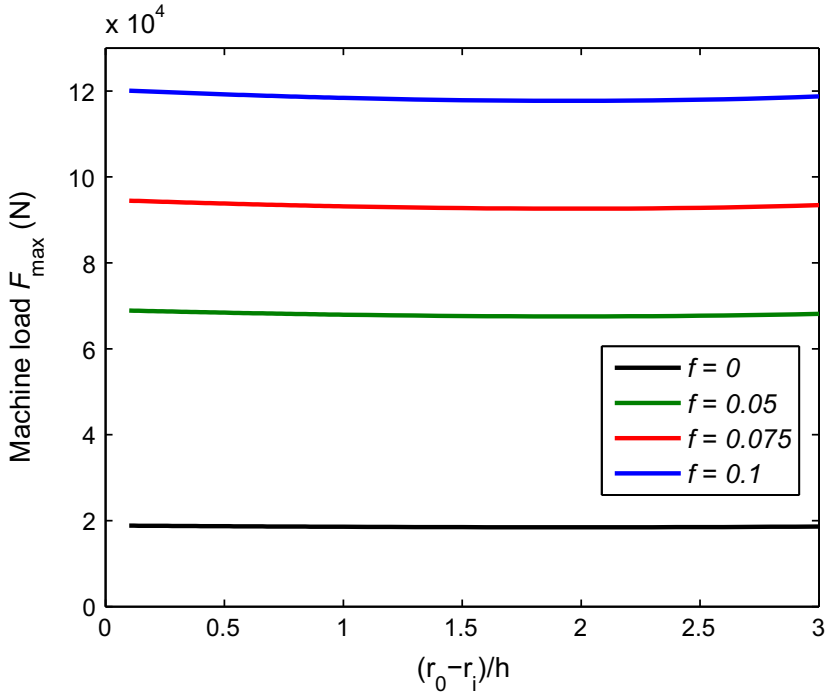

Fig. 6. Influence of female cone thickness on maximal machine load for different friction coefficients for $\alpha=1^{\circ}$.

Figs. 7 and 8 show the pressure and displacement distribution for 3 different positions of the support: $r_{s i}=62.1 \mathrm{~mm}, r_{s i}=70.3 \mathrm{~mm}$ and $r_{s i}=78.6 \mathrm{~mm}$. The external support radius is also changed in order to have the same support thickness. By keeping the support away from the male cone, the shear and bending deformation of the female cone make the pressure and displacement distribution dissymmetric. Thus, it is demonstrated that the support should be as close as possible to the male cone. However, the pressure field exhibits two peaks near the upper and lower edges of the ring.

The support thickness was also studied and results show that this parameter has no significant effect on the pressure and displacement distribution. Nevertheless, the support should be thick enough to avoid a high stress concentration near point $B$ defined in Fig. 4.

\subsection{Choice of female cone thickness}

As the radius $r_{0}$ of the tested ring is imposed, the female cone thickness depends only on the internal mean radius of the cone $r_{i}$. The choice of female cone thickness is discussed below from the two main functional requirements.

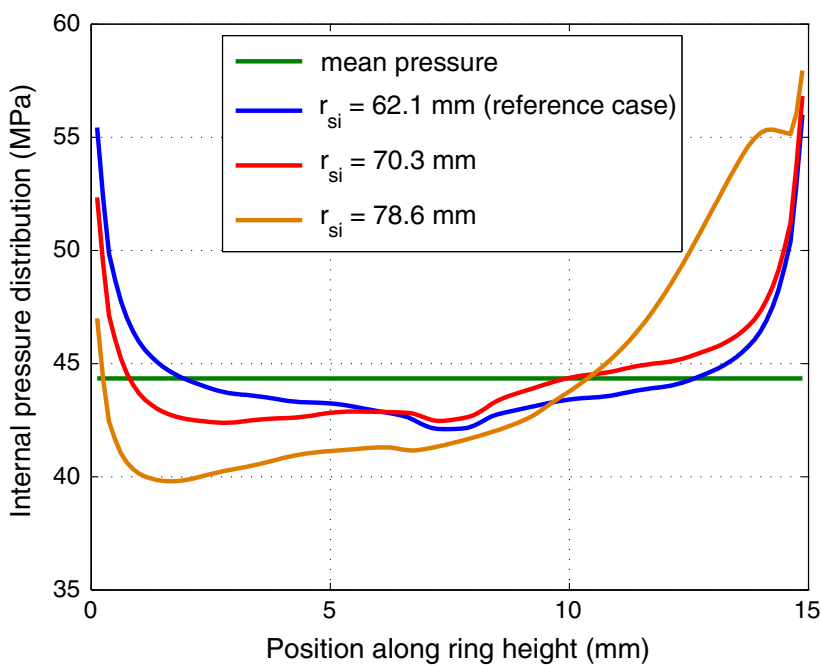

Fig. 7. Pressure distribution for three different positions of the support. 
4.4.1. Influence of female cone thickness on pressure uniformity

The influence of female cone thickness on pressure uniformity was investigated using the FEM presented in the previous part with the same configuration. The influence of the ring height $h$ was also studied and it can be concluded that the non-dimensional parameter $\left(r_{0}-r_{i}\right) / h$ is fully representative of the interaction between the influence of both female cone thickness and ring height. Fig. 9 presents the evolution of the non-uniformity pressure indicator versus $\left(r_{0}-r_{i}\right) / h$. The non-uniformity pressure indicator is defined by:

$f_{u}=\frac{\sigma_{p}}{p_{0}^{\text {mean }}}$

where $p_{0}^{\text {mean }}$ is the mean pressure applied to the ring and $\sigma_{p}$ is the standard deviation of the pressure distribution.

The results show that the non-uniformity indicator presents a minimum value close to $1.6 \%$ for $\left(r_{0}-r_{i}\right) / h=0.26$. Moreover, it is worth noting that the non-uniformity indicator never exceeds $6 \%$.

\subsubsection{Influence of female cone thickness on pressure measurement precision}

As mentioned in a previous section, evaluation of the pressure applied to the ring consists in using the female cone as a load sensor. The pressure applied to the ring can be extracted from Eqs. (1), (5), and (6) of the analytical model:

$p_{0}=\frac{s_{00} s_{i i}}{s_{00} s_{i i}-s_{i 0} s_{0 i}}\left(\frac{u_{0}}{s_{00}}-\frac{s_{0 i} \tan \alpha}{s_{00} s_{i i}} d\right)$

To calculate $p_{0}$ requires the material and geometrical properties of the female cone, and the measurement of the cross head displacement and the internal displacement of the tested ring during the test. The uncertainty of the estimate of the pressure can be expressed according to the uncertainty of each parameter:

$$
\begin{aligned}
\delta p_{0}= & \frac{\partial p_{0}}{\partial E} \delta E+\frac{\partial p_{0}}{\partial v} \delta v+\frac{\partial p_{0}}{\partial r_{0}} \delta r_{0}+\frac{\partial p_{0}}{\partial r_{i}} \delta r_{i}+\frac{\partial p_{0}}{\partial \alpha} \delta \alpha+\frac{\partial p_{0}}{\partial u_{0}} \delta u_{0} \\
& +\frac{\partial p_{0}}{\partial d} \delta d
\end{aligned}
$$

This expression can be changed to highlight the relative uncertainty of each parameter:

$$
\begin{aligned}
\frac{\delta p_{0}}{p_{0}}= & \chi_{E} \frac{\delta E}{E}+\chi_{v} \frac{\delta v}{v}+\chi_{r_{0}} \frac{\delta r_{0}}{r_{0}}+\chi_{r_{i}} \frac{\delta r_{i}}{r_{i}}+\chi_{\alpha} \frac{\delta \alpha}{\alpha}+\chi_{u_{0}} \frac{\delta u_{0}}{u_{0}}+\chi_{d} \\
& \times \frac{\delta d}{d}
\end{aligned}
$$

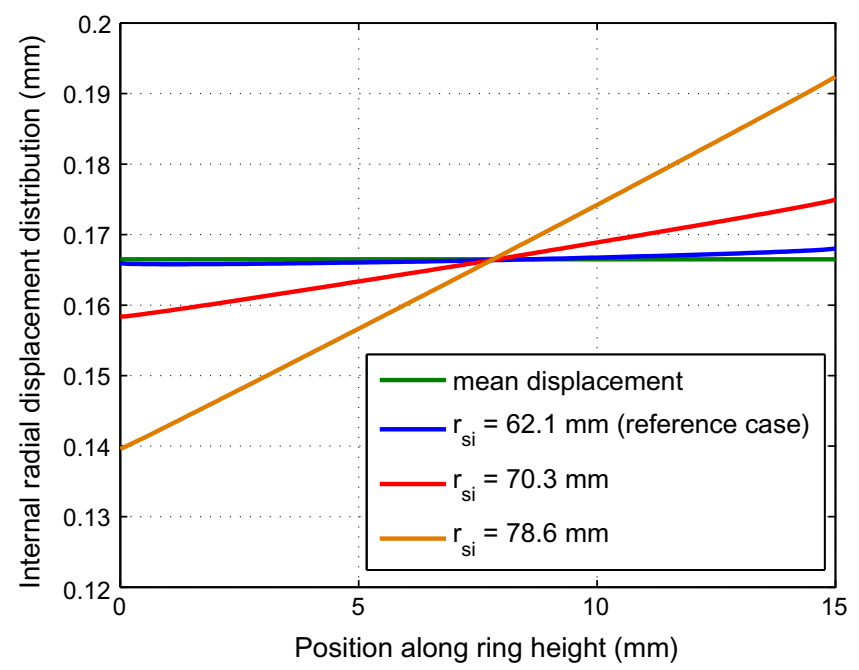

Fig. 8. Displacement distribution for 3 different positions of the support.

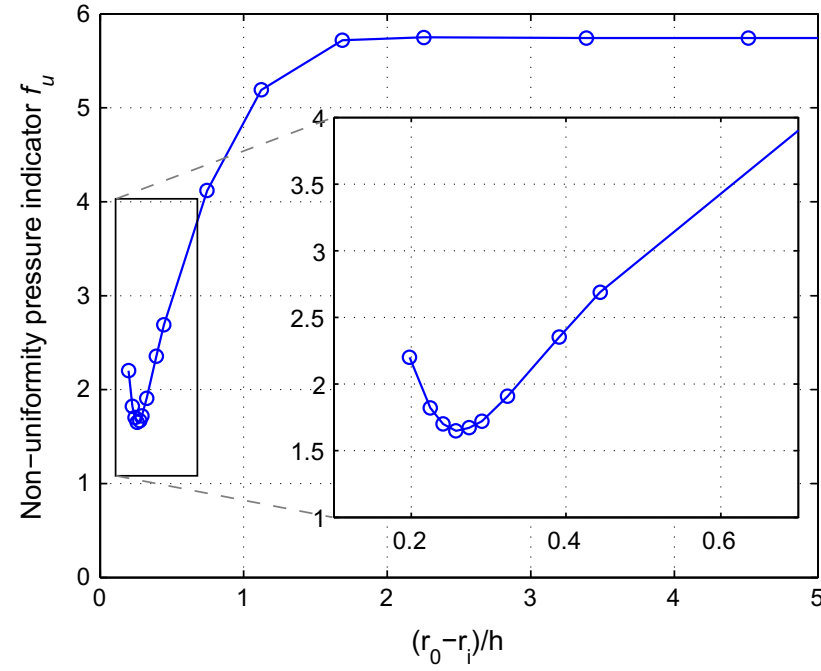

Fig. 9. Evolution of the non-uniformity pressure indicator versus $\left(r_{0}-r_{i}\right) / h$.

where non-dimensional parameters $\chi_{v_{i}}$ are defined by:

$\chi_{V_{i}}=\left|\frac{\partial p_{0}}{\partial V_{i}} \frac{V_{i}}{p_{0}}\right|$

Thus, the relative uncertainty generated by each parameter is equal to the relative uncertainty of the considered parameter multiplied by the non-dimensional parameter $\chi_{v_{i}}$.

The measurement method and relative uncertainty of each parameter are presented in Table 3. $u_{0}$ can be measured with a field displacement measurement technique (Digital Image Correlation) or using strain gauges placed on the external face for a thin ring. In both cases, the relative uncertainty will be less than 0.02 .

It is more difficult to measure precisely the Young modulus $E$ of the polymer which constitutes the female cone. Indeed, the behaviour of polymer materials is highly dependent on the loading rate, the stress state and the manufacturing process [22]. Thus, in order to reduce the relative uncertainty on $E$, a specific procedure is proposed in the next section to deal with this point.Concerning the non-dimensional parameters $\chi_{v_{i}}$, they are calculated from Eq. (15) and lead to $\chi_{E}=1, \chi_{v}<0.2, \chi_{r_{0}} \approx 1$ and $\chi_{r_{i}}$ approx 1 . $\chi_{\alpha}, \chi_{u_{0}}$ and $\chi_{d}$

\begin{tabular}{|c|c|c|c|c|}
\hline Parameter & $\begin{array}{l}\text { Measurement } \\
\text { method or source }\end{array}$ & $\begin{array}{l}\text { Relative } \\
\text { uncertainty } \\
\delta V_{i} / V_{i}\end{array}$ & $\begin{array}{l}\text { Adimensiona } \\
\text { parameter } \chi_{l}\end{array}$ & \\
\hline E & Metallic ring test & 0.05 & 1 & \\
\hline V & Material datasheet & 0.05 & 0.1 & \\
\hline$r_{0}$ & $\begin{array}{l}\text { 3D measuring } \\
\text { machine }\end{array}$ & 0.01 & $\approx 1$ & \\
\hline \multirow[t]{2}{*}{$r_{i}$} & $\begin{array}{l}\text { 3D measuring } \\
\text { machine }\end{array}$ & 0.01 & $\approx 1$ & \\
\hline & & & $\begin{array}{l}\left(r_{0}-r_{i}\right) / \\
h=0.26\end{array}$ & $\begin{array}{l}\left(r_{0}-r_{i}\right) / \\
h=3\end{array}$ \\
\hline$u_{0}$ & $\begin{array}{l}\text { Digital image } \\
\text { correlation or strain } \\
\text { gages }\end{array}$ & 0.02 & 2.8 & 1.25 \\
\hline$d$ & $\begin{array}{l}\text { Testing machine } \\
\text { sensor }\end{array}$ & 0.005 & 3.8 & 0.25 \\
\hline \multirow[t]{3}{*}{$\alpha$} & $\begin{array}{l}\text { 3D measuring } \\
\text { machine }\end{array}$ & 0.01 & 3.8 & 0.25 \\
\hline & & & $\begin{array}{l}\text { Relative } \\
\text { uncertainty }\end{array}$ & $\delta P_{0} / P_{0}$ \\
\hline & & & 0.188 & 0.104 \\
\hline
\end{tabular}

Table 3

Measurement method, relative uncertainty and dimensional parameters $\chi_{v_{i}}$ associated to each parameter. 


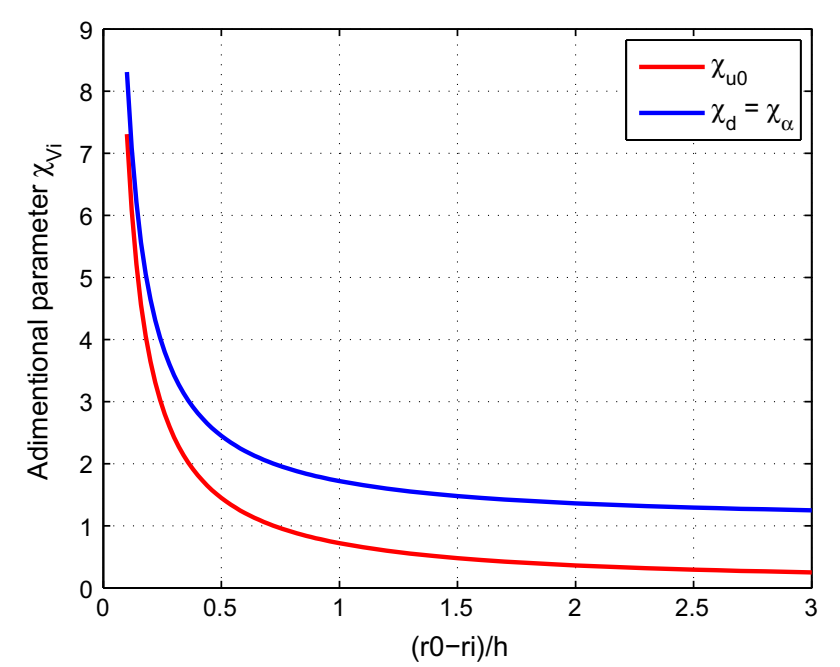

Fig. 10. Evolution of $\chi_{u_{0}}$ and $\chi_{d}$ versus $\left(r_{0}-r_{i}\right) / h$ for the base configuration with a $9.35 \mathrm{~mm}$ thick steel ring.

depend on the female cone thickness and they can be much greater than 1. Their method of calculation is detailed in Appendix A.

Thus, precision in pressure measurement is directly related to the value of $\chi_{\alpha}, \chi_{u_{0}}$ and $\chi_{d}$ and consequently to the value of $r_{0}-r_{i}$. As mentioned in Appendix A, these three parameters are linked to the stiffness contrast between the female cone and the tested ring. The evolution of $\chi_{\alpha}, \chi_{u_{0}}$ and $\chi_{d}$ versus $\left(r_{0}-r_{i}\right) / h$ is plotted in Fig. 10 for the base configuration previously defined with a $9.35 \mathrm{~mm}$ thick steel ring. First, the higher $\left(r_{0}-r_{i}\right) / h$ is, the lower $\chi_{\alpha}, \chi_{u_{0}}$ and $\chi_{d}$ are. But, for a given ring height $h$, the pressure measurement precision criterion appears to conflict with the pressure uniformity criterion. Indeed, as demonstrated previously, $\left(r_{0}-r_{i}\right) / h$ should be close to 0.26 to minimise the pressure nonuniformity which would lead to $\chi_{u_{0}}$ and $\chi_{d}$ being close to 3 . Thus, the choice of $\left(r_{0}-r_{i}\right) / h$ results in a compromise between the two criteria. In Table 3, non-uniformity indicator and uncertainty on $p_{0}$ measurement are presented for two choices of $\left(r_{0}-r_{i}\right) / h$. The first choice aims at minimising pressure non-uniformity and the second aims at minimising uncertainty on $p_{0}$ measurement.

\section{Application to a thick composite ring}

\subsection{Experimental protocol and test calibration}

First, the three parts of the test device (support, male and female cones) are designed and manufactured from specific functional requirements associated to the geometry and the material of the tested ring. The choice of female cone thickness $\left(r_{0}-r_{i}\right) / h$ is based on a compromise between pressure non-uniformity and uncertainty on $p_{0}$ measurement. Clearance between the tested ring and the female cone must be low (a slight interference-fit is better) in order to avoid the female cone being pre-stressed before the tested ring is loaded.

Next, the male cone is coated with a solid lubricant. The tested ring is placed around the female cone and, as shown in Fig. 11, the test device is put on the testing machine. According to the ring thickness and the objective of the test, different measurement techniques can be placed on the sample: strain gauges, displacement sensors or field displacement measurement.

As mentioned previously, the Young modulus of the polymer needed for the pressure measurement is difficult to measure with a classical sample. A calibration procedure is proposed to measure the Young modulus of the polymer in a configuration representative of the test. This procedure consists in testing one or more

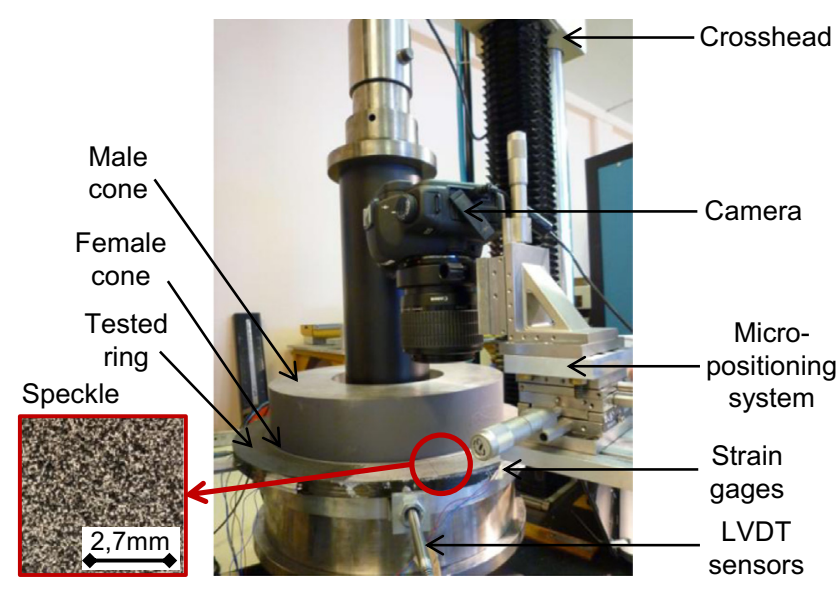

Fig. 11. Experimental set-up of the ring test.

standard rings made of a well-known material. The Young modulus $E$ of the polymer material can then be calculated using Eq. (13) by replacing the pressure applied to the standard ring by the pressure calculated from an elastic thin ring model :

$p_{0}=\frac{\varepsilon_{\theta \theta} e_{r} E_{r}}{r_{0}}$

where $e_{r}$ and $E_{r}$ are respectively the thickness and the Young modulus of the standard ring, $\varepsilon_{\theta \theta}$ is the hoop strain measured on the external surface of the standard ring.

Two steel rings of $81.25 \mathrm{~mm}$ radius with two different thicknesses $(4.25 \mathrm{~mm}$ and $9.35 \mathrm{~mm}$ ) were used as standard rings to measure the Young modulus of the polymer. The first ring gives $E=2.78 \mathrm{GPa}$ and the second ring gives $E=2.85 \mathrm{GPa}$.

\section{Results}

As mentioned in the introduction, the storage of hydrogen in the form of a gas requires high pressure (700 bar) tanks. Current certification standards require manufacturers to test their structures to three times the working pressure. This in turn means that composite walls of about $30 \mathrm{~mm}$ or $40 \mathrm{~mm}$ thick must be designed, according to vessel diameter. Due to the filament winding process, for such thick composite parts, variability of material properties and residual strains through the thickness can be considerable $[1,23,24]$.

The test proposed here allows the material to be tested on a representative specimen: a ring directly extracted from a thick composite vessel. The objective of tests is therefore to determine the strain distribution in the thickness and compare it to the model in order to highlight the influence of property variability and thickness gradient.The tested ring was extracted from the cylindrical part of a vessel made of 57 layers according the following lay-up: $\left[\left( \pm 15 / \pm 25 / 90_{2} / \pm 35 / \pm 45 / 90_{2}\right)_{7} / 90\right]$, producing a $39 \mathrm{~mm}$ thick composite. The ring radius and height are respectively $r_{0}=155.9 \mathrm{~mm}$ and $h=15 \mathrm{~mm}$. The fibre used is an intermediate modulus carbon fibre with an ultimate strain close to $1.3 \%$. The mean internal radius of cones $r_{i}$ was selected in order to ensure applied pressure uniformity according to the rule defined in part 4.4.1. The selected value, $r_{i}=151.25 \mathrm{~mm}\left(\left(r_{0}-r_{i}\right) / h=0.31\right)$, leads to a non-uniformity pressure indicator equal to $2 \%$ and an uncertainty on $p_{0}$ measurement equal to $18.8 \%$.

Fig. 11 shows the experimental device. Several measurement types were added to classical measurements (load cell data, crosshead displacement). Five strain gages and five LVDT sensors were placed around the ring on the external side in order to control the overall uniformity of ring deformation. In addition, a black 


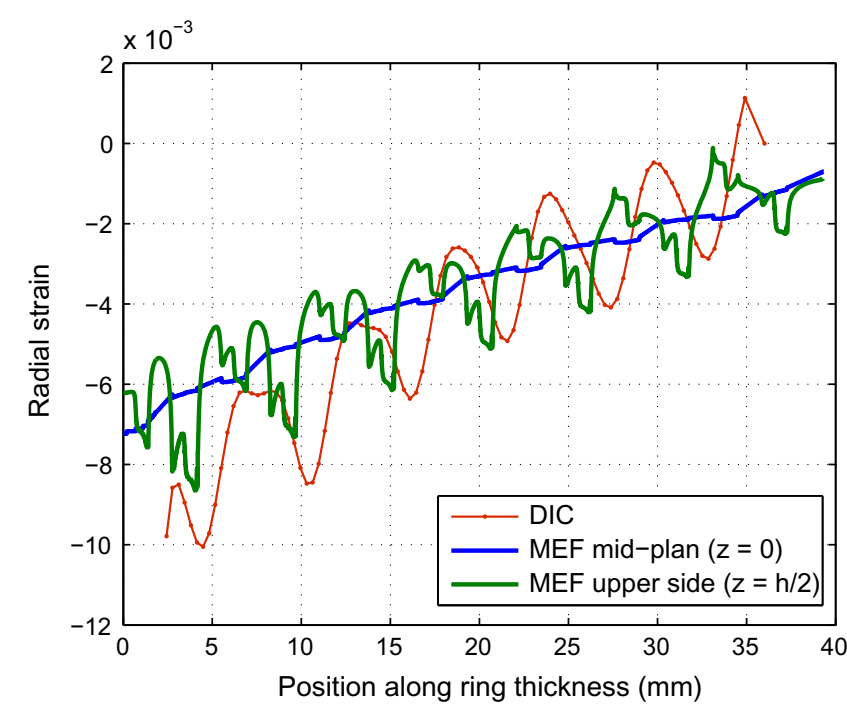

Fig. 12. Comparison between experimental (DIC) and FEM results on radial strains for a radial displacement $u_{0}$ of $0.67 \mathrm{~mm}$.

and white speckle was painted on the upper side of the ring and continuously observed with a camera in order to follow the displacement and strain fields through the thickness of the ring. Vic 2D software was used for Digital Image Correlation (DIC). The crosshead displacement rate was set to $2 \mathrm{~mm} / \mathrm{min}$ which gives an external hoop strain rate close to $2.10^{-6} \mathrm{~s}^{-1}$. The test was stopped when the maximal load capacity of the tensile machine was reached $(100 \mathrm{kN})$. The radial displacement $u_{0}$ was then equal to $0.67 \mathrm{~mm}$. Using Eqs. (15) and (17), the internal pressure is estimated at $750 \pm 140$ bar (ring stiffness equal to $1119 \pm 210 \mathrm{bar} /$ $\mathrm{mm}$ ). This value agrees well with the prediction in Table 1 calculated from material supplier documentation (ring stiffness equal to $930 \mathrm{bar} / \mathrm{mm}$ ).

As the ring consists of different angles, the upper and lower sides are subjected to edge effect that generates a 3-D strain state and change of strain field from the mid-plan $(z=0)$ to the upper and lower side $(z= \pm h / 2)$ [25]. This phenomenon was studied using the FEM presented in Section 3.2.2. Refined mesh (80 quadratic elements per layer) is needed to capture the edge effect. Figs. 12 and 13 show the evolution of radial and hoop strains according to the position along the ring thickness in mid-plan $(z=0)$ and the upper side

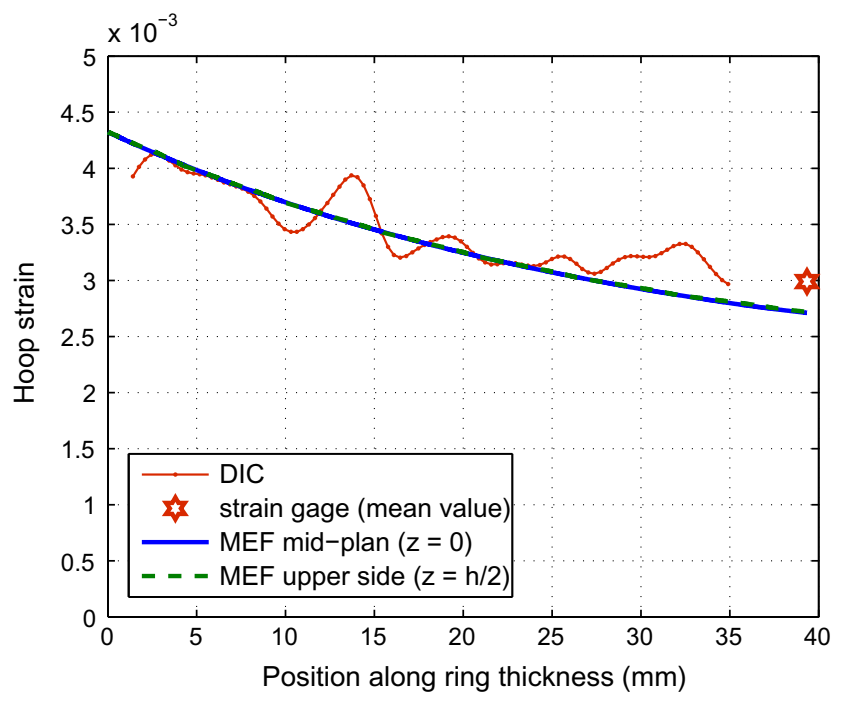

Fig. 13. Comparison between experimental (DIC) and FEM results on hoop strains for a radial displacement $u_{0}$ of $0.67 \mathrm{~mm}$. $(z=h / 2)$. Circumferential strains are clearly not altered by the edge effect, while radial strains are subjected to variation related to angle sequence. Strain fields deduced from DIC techniques are also plotted in Figs. 12 and 13. The strain obtained with gages on the external radius (red star on Fig. 13) is in the continuation of DIC measurement. The displacement field is evaluated on a 65 pixel $\times 65$ pixel square which gives a spatial resolution of $0.57 \mathrm{~mm}$. The FEM and experimental results are in good agreement, even if variation related to edge effect cannot be precisely captured with a spatial resolution close to composite layer thickness.

The prototype vessel used for this test was made with an optimal process sequence which is the result of many years of practice of our industrial partner. This process sequence is therefore the guarantee of reducing material heterogeneities. Thus, the property variability and thickness gradient identified elsewhere [1] are too low to be highlighted in the test presented above. However, the current process sequence duration (greater than $24 \mathrm{~h}$ ) is liable to be reduced in a cost versus quality optimisation. The new test device proposed in this paper aims to be the characterisation tool used during this optimisation procedure.

\section{Conclusions}

In this paper we proposed a new device to test thick rings under internal pressure based on a conical fitting. The innovative aspect resides in the ability to reach high pressures (over 700 bar) while keeping the lateral faces free for observation.

The methodology presented here is intended to optimise the choice of device design parameters according to functional requirements. This methodology is based on both analytical and finite element models. The internal pressure applied to the tested ring can then be analytically derived from the deformation of the intermediate female cone. The uncertainty over the estimate of the pressure can be evaluated from uncertainty on each parameter participating in the pressure formula.

The device is applied to the study of a $39 \mathrm{~mm}$ thick hydrogen storage vessel. Thanks to the original concept of the device, the strain field on a lateral face can be monitored using Digital Image Correlation.

In future studies, this test device will also be used to observe damage mechanisms and in particular to study the effects of material heterogeneities and property gradients. To do this, a microscope can be used instead of the camera in order to follow damage evolutions and strain gradients using fibre matrix patterns like the DIC speckle pattern.

\section{Acknowledgements}

This work was supported by OSEO agency. The authors would like to thank Air Liquide and EADS Composites Aquitaine for their technical support in the H2E project.

\section{Appendix A.}

By transferring Eqs. (7)-(10) in Eq. (15), we obtain the detailed expression of the pressure applied to the ring:

$$
\begin{aligned}
& p_{0}=\frac{E\left(v-\frac{r_{i}^{2}+r_{0}^{2}}{r_{0}^{2}-r_{i}^{2}}\right)\left(\frac{r_{i}^{2}+r_{0}^{2}}{r_{0}^{2}-r_{i}^{2}}+v\right)}{\left(v-\frac{r_{i}^{2}+r_{0}^{2}}{r_{0}^{2}-r_{i}^{2}}\right)\left(\frac{r_{i}^{2}+r_{0}^{2}}{r_{0}^{2}-r_{i}^{2}}+v\right)+\left(\frac{2 r_{0} r_{i}^{2}}{r_{0}^{2}-r_{i}^{2}}\right)^{2}} \\
& \left(\frac{u_{0}}{r_{0}\left(v-\frac{r_{i}^{2}+r_{0}^{2}}{r_{0}^{2}-r_{i}^{2}}\right)}-\frac{2 r_{i} \tan \alpha d}{\left(r_{0}^{2}-r_{i}^{2}\right)\left(v-\frac{r_{i}^{2}+r_{0}^{2}}{r_{0}^{2}-r_{i}^{2}}\right)\left(v+\frac{r_{i}^{2}+r_{0}^{2}}{r_{0}^{2}-r_{i}^{2}}\right)}\right)
\end{aligned}
$$


In order to simplify the following calculation, we note:

$A=\frac{\left(v-\frac{r_{i}^{2}+r_{0}^{2}}{r_{0}^{2}-r_{i}^{2}}\right)\left(\frac{r_{i}^{2}+r_{0}^{2}}{r_{0}^{2}-r_{i}^{2}}+v\right)}{\left(v-\frac{r_{i}^{2}+r_{0}^{2}}{r_{0}^{2}-r_{i}^{2}}\right)\left(\frac{r_{i}^{2}+r_{0}^{2}}{r_{0}^{2}-r_{i}^{2}}+v\right)+\left(\frac{2 r_{0} r_{i}}{r_{0}^{2}-r_{i}^{2}}\right)^{2}}$

$B=r_{0}\left(v-\frac{r_{i}^{2}+r_{0}^{2}}{r_{0}^{2}-r_{i}^{2}}\right)$

$C=\frac{2 r_{i}}{\left(r_{0}^{2}-r_{i}^{2}\right)\left(v-\frac{r_{i}^{2}+r_{0}^{2}}{r_{0}^{2}-r_{i}^{2}}\right)\left(v+\frac{r_{i}^{2}+r_{0}^{2}}{r_{0}^{2}-r_{i}^{2}}\right)}$

Thus, $p_{0}$ can be expressed simply as follows:

$p_{0}=E A\left(\frac{u_{0}}{B}-C \tan \alpha d\right)$

$p_{0}$ being proportional to $E$, we obtain:

$\chi_{E}=1$

The calculation of $\chi_{u_{0}}$ gives:

$\chi_{u_{0}}=\left|\frac{u_{0}}{u_{0}-B C \tan \alpha d}\right|$

The calculation of $\chi_{d}$ gives:

$\chi_{d}=\left|\frac{B C \tan \alpha d}{u_{0}-B C \tan \alpha d}\right|=\left|\chi_{u_{0}}-1\right|$

The calculation of $\chi_{\alpha}$ gives for $\alpha \ll 1$ :

$\chi_{\alpha}=\left|\frac{B C d\left(1+\tan ^{2} \alpha\right) \alpha}{u_{0}-B C \tan \alpha d}\right| \approx\left|\frac{B C d \alpha}{u_{0}-B C \tan \alpha d}\right|=\left|\chi_{u_{0}}-1\right|$

From Eq. (A.5), $\chi_{u_{0}}$ can also be expressed as follows:

$\chi_{u_{0}}=\left|\frac{E A}{B}\right|\left(\frac{p_{0}}{u_{0}}\right)^{-1}$

$p_{0} / u_{0}$ is the apparent stiffness of the tested ring (unit $\mathrm{Pa} / \mathrm{mm}$ ) while $|E A / B|$ represents the apparent stiffness of the female cone according to its specific loading conditions. Thus, $\chi_{u_{0}}$ represents a stiffness contrast between the female cone and the tested ring. The more compliant the female cone compared to the tested ring, the lower are $\chi_{\alpha}, \chi_{u_{0}}$ and $\chi_{d}$.

\section{References}

[1] Pilato A. Caractérisation des structures composites bobinées épaisses, application à l'étude du comportement de réservoirs de stockage d'hydrogène. PhD thesis, Bordeaux I University, France; December 2011.
<http://ori-oai.u-bordeaux1.fr/pdf/2011/PILATO_AURELIE_2011.pdf> laccessed March 2013.

[2] ASTM Standard D1599. Resistance to short-time hydraulic pressure of plastic pipe, tubing and fittings; 2005

[3] Hwang T-K, Park J-B, Kim H-G. Evaluation of fiber material properties in filament-wound composite pressure vessels. Compos Part A Appl Sci Manuf 2012;43:1467-75.

[4] ASTM Standard D2290. Apparent hoop tensile strength of plastic or reinforced plastic pipe by split disk method. West Conshohocken, PA: ASTM International; 2008.

[5] Walsh EJ, Adams DO. Development and evaluation of the quadrant ring test method. Exp Mech 2008;48:319-26.

[6] Laiarinandrasana L, Devilliers C, Oberti S, Gaudichet E, Fayolle B, Lucatelli JM. Ring tests on high density polyethylene: full investigation assisted by finite element modeling. Int J Press Ves Pip 2011;88:1-10.

[7] Tischler C, Kratochvilla TR, Muschik H, Dragaun H. Notched ring test for measuring slow cracking resistance in plastics pipes and fittings. Macromol Sym 2010;296:626-31.

[8] Pyo S, Tischler C, Choi S, Moon J. On-set slow cracking time detection for the Notched Ring Test. Polym Test 2010;29:453-8.

[9] Cain J, Case S, Lesko J. Testing of hygrothermally aged e-glass/epoxy cylindrical laminates using a novel fixture for simulating internal pressure. J Compos Constr 2009:13:325-31.

[10] Cohen D, Toombes YT, Johnson AK, Hansen MF. Pressurized ring test for composite pressure vessel hoop strength and stiffness evaluation. J Compos Technol Res 1995;17:331-40.

[11] Kempner EA, Hahn HT. Effect of radial stress relaxation on fibre stress in filament winding of thick composites. Compos Manuf 1995;6:67-77.

[12] Cohen D. Influence of filament winding parameters on composite vessel quality and strength. Compos Part A Appl Sci Manuf 1997;28:1035-47.

[13] Rousseau J, Perreux D, Verdière N. The influence of winding patterns on the damage behaviour of filament-wound pipes. Compos Sci Techno 1999;59:1439-49.

[14] Olivier P, Cottu JP, Ferret B. Effects of cure cycle pressure and voids on some mechanical properties of carbon/epoxy laminates. Composites 1995;26:509-15.

[15] Santulli C, Gil RG, Long AC, Clifford MJ. Void content measurements in commingled E-glass/polypropylene composites using image analysis from optical micrographs. Sci Eng Compos Mater 2002;10:77-90.

[16] Liu L, Zhang BM, Wang DF, Wu ZJ. Effects of cure cycles on void content and mechanical properties of composite laminates. Compos Struct 2006;73:303-9.

[17] Mertiny P, Ellyin F. Influence of the filament winding tension on physical and mechanical properties of reinforced composites. Compos Part A Appl Sci Manuf 2002;33:1615-22.

[18] Huang H, Talreja R. Effects of void geometry on elastic properties of unidirectional fiber reinforced composites. Compos Sci Technol 2005;65:1964-81.

[19] Varna J, Joffe R, Berglund LA, Lundström TS. Effect of voids on failure mechanisms in RTM laminates. Compos Sci Technol 1995;53:241-9.

[20] Costa ML, De Almeida SFM, Rezende MC. Critical void content for polymer composite laminates. AIAA J 2005;43:1336-41.

[21] D3039/D3039M-08. Standard test methods for tensile properties of polymer matrix composites materials. ASTM International; 2009.

22] Shan G-F, Yang W, Yang M -b, Xie B -h, Feng J -m, Fu Q. Effect of temperature and strain rate on the tensile deformation of polyamide 6. Polymer 2007;48:2958-68.

[23] Parlevliet PP, van der Werf WAW, Bersee HEN, Beukers A. Thermal effects on microstructural matrix variations in thick-walled composites. Compos Sci Technol 2008;68:896-907.

[24] Ha SK, Jeong JY. Effects of winding angles on through-thickness properties and residual strains of thick filament wound composite rings. Compos Sci Technol 2005;65:27-35.

[25] Herakovich CT. Edge effects and delamination failures. J Strain Anal Eng Des 1989;24:245-52. 